\title{
Free and Open Source Software \& the Mystery of Software Patent Licenses
}

\author{
Author Anna Haapanen, ${ }^{a}$ \\ (a) Visiting Senior Scholar at \\ Stanford University School of Law, \\ California
}

DOI: $\underline{10.5033 / \text { ifosslr.v7i1.107 }}$

\begin{abstract}
Despite the fact that the first FOSS licenses were drafted nearly three decades ago, there still exists great confusion even among the experienced technology lawyers and IT professionals as to what are the actual (express or implied) patent license grants - if any - conferred under the most common FOSS licenses, such as the GPLv2, the BSD license and the MIT license. This article discusses the possible outcomes in the light of a recent FOSS case litigated in California.
\end{abstract}

\section{Keywords}

Law; information technology; Free and Open Source Software; implied patent license

\section{After three decades of open source license construction - Still no clarity on the scope of the license grants}

Use of free and open source software (FOSS) is wide spread - in fact, FOSS may be found almost everywhere: in operating systems, in business applications, and in many (if not most) consumer devices. The well-known advantages of FOSS include the low acquisition costs, innovative development model through collaboration, and maturity of the software due to reuse.

Despite the fact that the first FOSS licenses were drafted nearly three decades ago, there exists uncertainty even among some experienced technology lawyers and IT professionals as to what are the actual (express or implied) patent license grants - if any - conferred under some of the most common FOSS licenses: the GPLv2, the BSD and the MIT licenses. The reason for this is that there have been so few litigated cases and thus so few judicial decisions to provide needed clarity. 
For a software program to be correctly characterized as "open source", it must meet the Open Source Initiative's Open Source Definition, which requires the free use, copying, modification and distribution of the software. ${ }^{1}$ However, the specific license grants under the GPLv2, the BSD and the MIT licenses were drafted using concepts derived mainly from copyright law and not patent law. ${ }^{2}$ By way of example, the express license grants under the GPLv2 concern only the exclusive rights of a copyright holder, namely copying, modification and distribution of the code. ${ }^{3}$ The exclusive rights of a patent holder as enumerated in 35 U.S.C. Sec. 271(a), i.e. the rights to make, use, sell, offer for sale and import, are not mentioned within the license grants of the GPLv2. On the other hand, the GPLv2 includes the so called Liberty or Death clause, which prohibits (also) patent holders from distributing code under the GPLv2 and simultaneously claiming patent royalties from the licensees. ${ }^{4}$ Under the BSD license, in turn, redistribution and use of the software with or without modification is permitted subject to certain conditions. The BSD license therefore mentions only one of the five enumerated exclusive patent rights: "use." The MIT license recites both "using" and "selling" the software, and therefore mentions at least two of the five enumerated exclusive rights of a patent holder.

\section{The existence and scope of any patent license grants in popular open source licenses is, to date, unresolved}

Due to the ambiguity in the license grants of the most common FOSS licenses, questions have been posed as to what is the actual scope of patent license rights granted under these FOSS licenses, either expressly or implicitly. Specifically, the long debated topic has been whether licensing of software subject to the terms and conditions of the most common FOSS licenses triggers either an express license (based on the use of patent exclusive right verbs like "use" or "sell") or at least an implied patent license under the patents held by the copyright holder(s) and/or the subsequent redistributor(s). To date, these questions remain unresolved, as there has been no definitive federal or state court decisions in the United States (or for that matter,

1 See the Open Source Definition by the Open Source Initiative at http://opensource.org/osd. (Last visited April 14, 2015).

2 Interestingly, in the 1970s, there was substantial doubt about whether U.S. federal patent, copyright or any other federal protection would extend to computer software; accordingly, most licensing of computer software was accomplished under state trade secret and state confidentiality law protections. In the 1980s, with the passage of the Computer Software Copyright Act Amendments of 1980 (following the CONTU Commission studies in the 1970s), it was made clear that computer software was automatically protected upon creation by the Federal Copyright Act, but the patentability of software remained unclear. It was only with a number of decisions by the Federal Circuit in the 1990s that computer software patent protection was put beyond doubt. Some twenty years later, following the U.S. Supreme Court's decision in Alice v. CLS, 134 U.S. 2347 (2014), there remains no doubt that copyright protection extends to computer software, but the extent to which patent protection is available in the face of subject matter objections under 35 U.S.C. Section 101 has reopened the debate. To date, most post-Alice Section 101 subject matter defence motions have succeeded in invalidating over $80 \%$ of the software patents challenged, on Rule 12(b)(6) motions to dismiss.. It may be too early to tell if this is just the result of early challenges being against "bad" software patents improperly allowed by the PTO under historical norms, or whether a larger trend toward invalidating most software patents is occurring.

3 Sections 1 and 2 of the GPLv2.

4 Section 7 of the GPLv2. 
so far anywhere in the world) directly addressing the scope of any patent rights granted, under or in connection with, FOSS licenses.

The drafters of the GPLv2 were aware of the patent license issue; indeed, to remove the ambiguity regarding the scope of the patent license rights granted under the GPL v2, an explicit patent license was added into the GPLv3 in 2007. However, tens of millions of lines of code may be still governed by the GPLv2; in addition, vast amounts of code are subject to the permissive BSD and MIT licenses, which also do not address patent rights directly. Therefore, even around three decades after drafting of the first of these licenses, a lack of clarity still remains. As one FOSS lawyer put it: "The topic of what patent rights are licensed under GPLv2 is a subject of controversy — or better said, mystery." 5

What then should the FOSS community do to better understand the patent rights granted under, or in connection with, these licenses? Most FOSS compliance policies and procedures only address effectively the copyright issues, whereas the patent issues are often based upon educated guesses as to the exposure to one's own patent portfolio when contributing and/or distributing code under the GPLv2, the BSD and the MIT, or for that matter, what patent rights may have been received from third party patent holders under, or in connection with, these licenses.

The questions regarding any potential exposure to third party patents or to licensing one's own patents may not be of concern to many FOSS users and licensors, since it has not prevented the massive expansion of FOSS during the past three decades, by both independent software development projects as well as corporate users. ${ }^{6}$ Nevertheless, due to potential patent exposure - particularly corporate users with large patent portfolios and financial exposure to the patent portfolios of others -- may be less willing to use, or may require more strict review and clearance processes when using, FOSS.

\section{Recent FOSS litigations at a glance}

In order to provide some clarity to the unclear patent license grants in some of the commonlyused FOSS licenses, a few attempts have been made in the United States to analyze these licenses in light of patent case law of implied patent licensing and estoppel theories in

5 Meeker, Heather, J.: Open Source and the Age of Enforcement. Hastings Science and Technology Law Journal. (Vol. 4.2 Summer 2012) at 281.

6 According to Black Duck, more than $50 \%$ of all corporations are expected to use open source. See Black Duck: 2014 Future of Open Source Survey Results. Available at http://www.slideshare./net/blackducksoftware/2014-future-of-open-source-survey-results? $\underline{\text { related }=1}$ (Last visited April 9, 2015). 
general. ${ }^{7}$ Analysis of this topic in light of European law is even scarcer. ${ }^{8}$ Most often the question regarding potential implied patent licenses (under estoppel or other theories), and also patent exhaustion, in the context of FOSS licensing has been stated to be "beyond the scope of this article." While awaiting a definitive court decision on the specific questions regarding the scope of patent licenses under the most common FOSS licenses, guidance for the patent exposure analysis may only be found in court cases concerning implied patent licenses and estoppel in general, supplemented with analysis of the very few FOSS-related court decisions given so far.

Court decisions regarding construction of FOSS licenses are quite rare both in the United States and Europe, and at best give merely guidance on the very basic questions regarding FOSS licenses, such as enforceability, availability of injunctions for breach of license and the license condition versus contractual covenant debate. The first court decisions regarding enforcement of FOSS licenses were given in Europe. The primary issues resolved in early FOSS case law are that GPL is an enforceable license, and that injunctions are available for breach of GPL both in Europe ${ }^{9}$ as well as in the United States. ${ }^{10}$ Breach of FOSS license terms may also be considered as breach of license conditions as opposed to breach of contractual covenants, and accordingly, breach of license conditions may result in a finding of copyright infringement - thus making available the most powerful remedies, such as injunctions and statutory damages. The various benefits conferred by the FOSS licensing model may also constitute consideration - the third element required for enforceable contract in the United States in addition to the elements of offer and acceptance. ${ }^{11}$

\section{From FOSS enforcement for compliance to enforcement for commercial ends}

The first wave of GPL enforcement actions were initiated in Europe by Harald Welte through his gpl-violations.org-project, and in the United States by Software Freedom Law Center (SFLC). These lawsuits have been characterized as "enforcement for compliance." Both Welte and SFLC were successful in requiring the counter parties to obey all the terms and conditions of the GPLv2. By way of example, all of the complaints filed by SFLC with the United States District Court for the Southern District of New York (SDNY) during its first round of GPL violation lawsuits were rapidly settled, and the defendants agreed to appoint Open Source

7 See for example the very often cited writing by Pugh, Adam and Majerus, Laura A.: Potential Defenses of Implied Patent License Under the GPL (October 31, 2006) available at http://www.fenwick.com/docstore/Publications/IP/potential defenses.pdf (Last visited April 14, 2015). See also Haapanen, Anna: Patent Exhaustion and Implied Patent License in Connection with Free and Open Source Software. Research for the LL.M. Degree at Columbia Law School supervised by Professor Eben Moglen. (May 2009) and Nadan, Christian, H.: Closing the Loophole: Open Source Licensing \& the Implied Patent License. The Computer \& Internet Law (Volume 26. August 2009).

8 See Suchomski, Bernd: Proprietäres Patent Recht beim Einsatz von Open Source Software. Eine rechtiliche Analyse aus unternehmerischer sicht. (Medien, Internet und Recht 2011).

9 Welte v. Sitecom Deutschland GmbH, No. 21 O 6123/04 (District Court of Munich I) and Welte v. D-Link Deutschland GmbH, No. 2-6 0 224/06 (District Court of Frankfurt am Main).

10 Software Freedom Conservancy, Inc. v. Best Buy Co., Inc., No. 09 CV-10155 (S.D.N.Y. Jul 27, 2010).

11 Jacobsen v. Katzer, 535 F.3d 1373, (Fed. Cir. 2008). 
Compliance Officers and publish the source code for the GPL-licensed programs they were distributing. ${ }^{12}$ The second round of GPL enforcement complaints followed shortly thereafter in New York, at SDNY, resulting again in quick settlement of the complaints, and undertakings by the defendants to adhere to the obligations of the GPL. ${ }^{13}$ In addition to the GPLv2, the Artistic License has been tested in United States courts. The Court of Appeals for the Federal Circuit held that the terms of the permissive-type Artistic License are enforceable copyright conditions, the breach of which constitutes copyright infringement. ${ }^{14}$

While there is enough case law to establish that FOSS licenses are enforceable, the existing FOSS case law does not yet give much guidance on the scope of license rights actually conferred under the most common FOSS licenses. However, the FOSS community is facing a shift in enforcement actions - from enforcement for compliance to enforcement for commercial ends. By way of example, XimpleWare Corporation sued Versata and Ameriprise - as well as certain other defendants - for copyright and patent infringement based on use of GPL-licensed software. These litigations were clearly initiated for commercial ends, not (merely) for FOSS license compliance.

\section{High hopes of the XimpleWare litigation to bring greater clarity}

FOSS lawyers on the alert for a resolution of the patent issues in the GPLv2 have been waiting for a court decision in the XimpleWare litigation, anticipating that any decision could shed some light on the existence and scope of an implied patent license in the GPLv2. The XimpleWare litigation was mentioned as the number one of the top FOSS legal developments in year 2014, with anticipation that a court might finally interpret the scope of the license grants in the GPLv2. ${ }^{15}$ Businesses dependent on GPLv2-licensed software were advised to "watch this case carefully." ${ }^{16}$ Unfortunately, no guidance regarding interpretation of the GPLv2 license rights materialized in the form of a very detailed court opinion, since the XimpleWare litigation settled only a few weeks after being identified as a top 10 important case. However, it is still worth revisiting the case - both the Complaints and the various Motions to Dismiss submitted in the litigation - because they provide an interesting window into the arguments that might be made in the future for both rejecting and finding a patent license in the GPLv2.

Starting from the facts, XimpleWare had released an XML parser named VTD-XML under the GPLv2. XimpleWare was also granted three United States patents, and the VTD-XML software licensed under the GPLv2 was asserted by XimpleWare to practice each of the

12 The first round of complaints were filed by SFLC with the Southern District of New York in Fall of 2007 against Monsoon Multimedia Inc., Xterasys Corporation, High Gain Antennas, LLC and Verizon Communications Inc.

13 The second round of complaints were filed by SFLC with the Southern District of New York in summer 2008 against Bell Microproducts, Inc., Super Micro Computer, Inc. and Extreme Networks, Inc.

14 Jacobsen v. Katzer, 535 F.3d 1373 (Fed. Cir. 2008).

15 Radcliffe, Mark: Top 10 FOSS Legal Developments in 2014. (January 12, 2015) Available at: http://opensource.com/law/15/1/top-foss-legal-developments-2014 (Last visited April 13, 2014).

16 Williamson, Aaron: Software Litigation Opens Pandora's Box of Key Open Source Issues. (January/February 2015. Landslide. Vol 7. No. 3.)

International Free and Open Source Software Law Review Vol. 7, Issue 1 
independent claims of those patents. XimpleWare sued, among others, Versata and its customer Ameriprise, for both copyright and patent infringement based on use of the GPLv2licensed VTD-XML software. ${ }^{17}$ Versata allegedly incorporated the VTD-XML software into its proprietary Distribution Channel Management (DCM) product in violation of the GPLv2 license requirements for source code disclosure and licensing of derivatives only under the GPLv2. Since the VTD-XML software was embedded in the DCM product, XimpleWare claimed that also Versata's products necessarily practiced the independent claims of the XimpleWare patents.

Versata licensed its DCM product to Ameriprise under a proprietary ink-signed (and presumably directly negotiated) Master Licensing Agreement. Ameriprise, in turn, provided the DCM product, including the GPL-licensed VTD-XML software included with it, further to thousands of its franchise-based financial advisors - again allegedly without adhering to the terms and conditions of the GPLv2. XimpleWare also made the VTD-XML software available under commercial license terms, but neither Versata nor Ameriprise had bought a commercial license from XimpleWare. According to XimpleWare, Versata's exploitation of VTD-XML in breach of the GPLv2 constituted wilful infringement of XimpleWare's intellectual property rights due to the unauthorized use, making and selling of the DCM product without abiding by the terms of the GPLv2 license.

Accordingly, XimpleWare brought a suit against Versata and some of its customers, including among others, Ameriprise, United Healthcare Services and MetLife, for copyright and patent infringement. Ximpleware also accused Versata of induced and contributory patent infringement. Further, XimpleWare sought preliminary and permanent injunctive relief against Versata and its customers, seeking to enjoin the manufacture, production and sale of products practicing XimpleWare's patents, as well as an award of treble damages based on wilful infringement of XimpeWare's patents. ${ }^{18}$

As the Court commentary was on early motions and without any trial or evidentiary hearing, the analysis below is based on the pleading stage only. Therefore, it may not be taken to be definitive as to what a Federal Court (or ultimately the U.S. Supreme Court) would decide in the evaluation of any dual licensing approach where FOSS licensing under the GPLv2 is undertaken concurrently with proprietary licensing.

\section{Arguments against and in favor of express or implied patent license grants in the GPLv2}

XimpleWare's complaints, as amended, resulted in a few rounds of motions to dismiss by various defendants. The briefs in support of those motions provide an interesting preview for FOSS lawyers of how the issue of patent licenses in the GPLv2 might be argued. In its Second Amended Complaint against Versata, Ameriprise and other defendants, XimpleWare

17 For more detailed background of the case, see Ibid.

18 Complaint, Ximple WareCorp. v.Versata Software, Inc. (No. 3:13-cv-05160-SI) (N.D. Cal. Nov 5, 2013) (Copyright Complaint) and Complaint, XimpleWare Corp. v. Versata Software, Inc. (No. 5:13-cv-05160-SI-PSG) (N.D. Cal. Nov 5, 2013) (Patent Complaint). The Complaint(s) were amended on December 17, 2013 (Amended Complaint) and again on May 31, 2014 (Second Amended Complaint). 
claimed that the GPLv2 does not include a patent license, and the Preamble of the GPLv2, ${ }^{19}$ where it refers to patents, is not an operative part of the license. According to XimpleWare, only Sections $7^{20}$ and $8^{21}$ of the GPLv2 mention patents, but they do not grant a patent license. Accordingly, XimpleWare claimed that infringement of XimpleWare patents resulted from the use of Versata products without Versata or its customers entering a commercial license with XimpleWare. ${ }^{22}$

In its Motion to Dismiss the Second Amended Complaint, Versata and United Healthcare Services (UHS) noted that under Section 0 of the GPLv2,"the act of running a Program is not restricted." Therefore, any use of VTD-XML to perform the patented method was explicitly licensed under the GPL. ${ }^{23}$ UHS also referred to the Court's earlier Order dismissing claims against UHS on this ground. The Court held that "Because an express license is a defense to patent infringement, XimpleWare's direct infringement claims against Versata's customers turn on whether the customers' distribution is licensed under the GPL." Thus, the Court found

19 The preamble of GPLv2 references patents as follows:

[A]ny free program is threatened constantly by software patents. We wish to avoid the danger that redistributors of a free program will individually obtain patent licenses, in effect making the program proprietary. To prevent this, we have made it clear that any patent must be licensed for everyone's free use or not licensed at all.

20 Section 7 of the GPLv2 states that:

If, as a consequence of a court judgment or allegation of patent infringement or for any other reason (not limited to patent issues), conditions are imposed on you (whether by court order, agreement or otherwise) that contradict the conditions of this License, they do not excuse you from the conditions of this License. If you cannot distribute so as to satisfy simultaneously your obligations under this License and any other pertinent obligations, then as a consequence you may not distribute the Program at all. For example, if a patent license would not permit royalty-free redistribution of the Program by all those who receive copies directly or indirectly through you, then the only way you could satisfy both it and this License would be to refrain entirely from distribution of the Program. If any portion of this section is held invalid or unenforceable under any particular circumstance, the balance of the section is intended to apply and the section as a whole is intended to apply in other circumstances. It is not the purpose of this section to induce you to infringe any patents or other property right claims or to contest validity of any such claims; this section has the sole purpose of protecting the integrity of the free software distribution system, which is implemented by public license practices. Many people have made generous contributions to the wide range of software distributed through that system in reliance on consistent application of that system; it is up to the author/donor to decide if he or she is willing to distribute software through any other system and a licensee cannot impose that choice. This section is intended to make thoroughly clear what is believed to be a consequence of the rest of this License.

21 Under Section 8 of the GPLv2:

If the distribution and/or use of the Program is restricted in certain countries either by patents or by copyrighted interfaces, the original copyright holder who places the Program under this License may add an explicit geographical distribution limitation excluding those countries, so that distribution is permitted only in or among countries not thus excluded. In such case, this License incorporates the limitation as if written in the body of this License.

22 Second Amended Complaint, at 8,10 and 20.

23 Versata Software, Inc., F/K/A Trilogy Software, Inc., Trilogy Development Group, Inc. and Aurea Sotware, Inc. A/K/A Aurea, Inc.'s Notice of Motion and Motion to Dismiss the Second Amended Compliant, No. 5:13-cv-05161-SI-PSG (N.D. Cal. June 13, 2014.) at 6. 
that mere use of XimpleWare's patented source code was explicitly permitted under the GPLv2, while unlicensed distribution of the source code is not allowed. ${ }^{24}$ According to UHS, whether the provision in Section 0 of GPLv2 is termed a disclaimer, a waiver, or a statement estopping the licensor from later claiming a restriction against using the program, "GPL's language could not be clearer: running the software is categorically unrestricted." 25

Other defendants argued that any and all use of the software is permitted by the GPLv2, and thus the patent infringement claims should fail. ${ }^{26}$ MetLife and other defendants stated - with reference to the Court's earlier order - that the fact that a patent license is included in the GPLv2 was already decided by the Court. According to those defendants, "The law of the case here is unmistakable. The GPL includes a patent license." 27

Ameriprise stated - in its first motion to dismiss XimpleWare's First Amended Complaint that the entire point of open source software is that the software will be free to use. Accordingly, Ameriprise argued that the GPLv2 places no restrictions on any other use of the software, since activities other than copying, distribution and modification are not covered by the license - they are outside its scope, and because the act of running the program is not restricted. Further, according to Ameriprise, it became a licensed user of XimpleWare software when it received the software from Versata and thus retained its rights under the GPL, regardless of whether Versata lost its rights. As making use of the software was not contingent on compliance, and since Ameriprise did not modify the software or distribute copies of it, it had the right to use the GPL-licensed software without any restriction. ${ }^{28}$

UHS further argued that XimpleWare simply gave up its right to seek compensation for the mere use of that software, including compensation for any patent royalties, regardless of whether that use was authorized under a license, a waiver or an estoppel: ${ }^{29}$

Plaintiff chose to distribute its software to the public under the GPL for its own commercial reasons. In so doing, Plaintiff represented to the consuming public that mere use of its software was "not restricted." Plaintiff cannot wish that representation away now that it inconveniences its litigation strategy. Plaintiff's arguments amount to a "bait and switch," seeking to recover payment for mere use that Plaintiff, through its adoption of the GPL, told the world would be unrestricted.

24 Order Granting-in-Part Defendants' Motions to Dismiss, No. 5:13-cv-05161-SI-PSG (N.D. Cal. May 16, 2014) at. 9.

25 United Health Care Solutions' Notice of Motion and Motion to Dismiss the Second Amended Compliant, No. 5:13-cv-05161-SI-PSG (N.D. Cal. June 12, 2014.) at 9 and 10. See also Order Granting-in-Part Defendants' Motions to Dismiss, No. 5:13-cv-05161-SI-PSG (N.D. Cal May 16, 2014).

26 Waddel \& Reed Financial Inc.'s Notice of Motion and Motion to Dismiss the Second Amended Compliant, No. 5:13-cv-05161-SI-PSG (N.D. Cal. June 13, 2014.) at 4.

27 Pacific Life Inc. Co., Metropolitan Life Inc. Co., the Prudential Inc. Co of America, Wellmark, Inc. and Aviva USA Corp.'s Notice of Motion and Motion to Dismiss the Second Amended Compliant, No. 5:13-cv-05161-SI-PSG (N.D. Cal. June 13, 2014) at 11.

28 Ameriprise Inc. and Ameriprise Financial Inc.'s Notice of Motion and Motion to Dismiss the Amended Compliant, No. 5:13-cv-05161-SI-PSG (N.D. Cal. Dec. 31, 2013).

29 United HealthCare Services, Inc.'s Reply in Support of its Motion to Dismiss Second Amended Complaint. No. 5:13-cv-05161-SI-PSG (N.D. Cal. July 3, 2013). 


\section{Decisions from the case}

The Court in the XimpleWare litigation confirmed again in November 2014 that use of software is unrestricted under the GPLv2 - but that distribution is not. According to the Court, the GPL permits distribution only if the distributing party satisfies several specific conditions, such as including a copy of the GPL along with the distributed program. ${ }^{30}$ The Court dismissed XimpleWare's direct and wilful patent infringement claims against Versata's customers (except Ameriprise) and indirect patent infringement claims against Versata. However, the direct and wilful patent infringement claims against Versata and Ameriprise remained in the case. The Court gave XimpleWare the chance to amend its Complaint for the third time. Before there was any chance to further brief or consider to what extent direct and wilful patent infringement occurred as the result of Versata and Ameriprise's distributions of the GPLv2 licensed software without complying with those licenses, the case was settled.

\section{Conclusion}

The XimpleWare FOSS patent litigation was settled following Mediation on February 10, 2015 through the assistance of a retired federal judge, Hon. James Ware (Ret.), who was appointed as the Federal Mediator for the resolution of both the patent and the copyright claims brought by XimpleWare. ${ }^{31}$ Absent settlement of both the patent and copyright infringement proceedings, the litigation would have consumed two trials of substantial duration in the Federal Courts. However, because of the settlement, no further clarification was ever gained in this FOSS litigation regarding the question on the scope of any patent license under the GPLv2, other than the ruling in defendant's earlier motions to dismiss that the right to use is retained, as long as the license conditions of the distribution right are not breached. ${ }^{32}$ Therefore, one view of the decisions in the XimpleWare litigation is that it should be safe to assume that the GPLv2 does indeed include a right under the author's patents to at least use the software, since by the terms of the GPLv2, the right to use the software is explicitly unrestricted. Nevertheless, the other statutory patent rights - to make, to sell, to offer to sell, or to import - remain unresolved.

Another view is that the matter will not be settled until one or more definitive appellate rulings make clear whether the GPLv2 includes (or, based on the totality of the circumstances, may trigger) a patent license grant of any type (and if so, what is its scope). In reaching such a conclusion, the patent license grant would likely be analysed by implication - given that unlike the GPLv3 - the grant would probably be found to not be expressly present in the GPLv2. However, in all cases, all licensing attorneys knowledgeable of the GPL should agree that distribution of the GPL-licensed software is subject to compliance with the terms and conditions of the license, and non-compliance may result in loss of all of the granted rights. Still, many questions regarding the scope and extent of the patent remain until further, more definitive rulings emerge from the courts.

30 Order Granting-In-Part Defendants' Motions to Dismiss. No. 5:13-cv-05161-SI-PSG (N.D. Cal. Nov 25, 2014) at 11.

31 Notice of Settlement. No. 5:13-cv-05161-SI-PSG (N.D. Cal. Feb 10, 2015)

32 Order Granting-in-Part Defendants' Motions to Dismiss, No. 5:13-cv-05161-SI-PSG (N.D. Cal. May 16, 2014) at 9. 


\section{About the author}

Anna Haapanen is attorney at Roschier, licensed to practice law in Finland and New York. Currently Anna is on leave of absence as a Visiting Senior Scholar at Stanford University School of Law (California). Anna specializes in Technology, Media \& Telecommunications (TMT), IP/IT transactions, outsourcing and licensing with a focus on FOSS. She has previously worked at Software Freedom Law Center (SFLC) in New York and Nokia Open Source Legal in Finland. Anna holds an LL.M. from Columbia University, New York (with Stone Scholar honours), an LL.M. from the University of Helsinki and an M.Sc. Econ. from the Hanken Swedish School of Economics. Anna is recognized as a leading lawyer within TMT and IT in international directories such as Chambers and Partners and Who's Who Legal. Anna acts as Local Representative for Finland at the International Technology Law Association (ITechLaw), and is Member of the Board at the International Federation of Computer Law Associations (IFCLA). Anna has also acted as Chairman of the Board at the Finnish IT Law Association (2013\&14) and Secretary to the Board at the Finnish IT Law Association $(2011 \& 12)]$

\section{Licence and Attribution}

This paper was published in the International Free and Open Source Software Law Review, Volume 7, Issue 1 (December 2015). It originally appeared online at http://www.ifosslr.org.

This article should be cited as follows:

Haapanen, Anna (2015) 'Free and Open Source Software and the Mystery of Software Patent Licenses Under the GPL', International Free and Open Source Software Law Review, 7(1), pp $19-28$

DOI: 10.5033 ifosslr.v7i1.107

Copyright (C) 2015 Anne Haapanen.

This article is licensed under a Creative Commons 4.0 licence, share, adapt, attribution, CC-BY-4.0 available at

http://creativecommons.org/licenses/by/4.0/

As a special exception, the author expressly permits faithful translations of the entire document into any language, provided that the resulting translation (which may include an attribution to the translator) is shared alike. This paragraph is part of the paper, and must be included when copying or translating the paper.

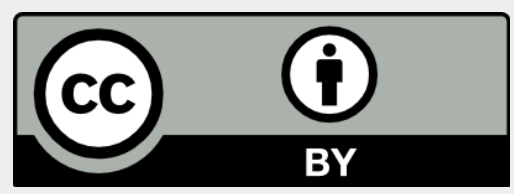

